\title{
Substance Flow Analysis of Tantalum in Taiwan
}

\author{
Feng-Chi Yen, Tien-Chin Chang* and Wen-Hong Xu \\ Institute of Environmental Engineering and Management, National Taipei University of Technology, Taipei 106, Taiwan
}

\begin{abstract}
Substance Flow Analysis (SFA) is mainly used to quantify flows and stocks of a particular substance distributed in a finite ecosystem. It can also be used to help decision-makers select the best strategy to implement resource allocation and management. This study focused on tantalum flow in Taiwan in 2013, specifically as tantalum capacitors, powder, and waste products. Tantalum, a rare metal that has a lot of potential, especially in the electronics industry, is not locally produced in Taiwan; so an SFA is vital to monitor supply, demand, and accumulation. Best estimates were done in coordination with Taiwan companies and government agencies, namely: Ministry of Economic Affairs; Ministry of Finance; Customs Department; and Environmental Protection Administration. In 2013, Taiwan imported a total of 340,355 kg of tantalum; $84.5 \%$ of this remained in Taiwan either as electronic products or as raw materials, while the rest were exported. [doi:10.2320/matertrans.M2015420]
\end{abstract}

(Received November 26, 2015; Accepted February 15, 2016; Published April 8, 2016)

Keywords: tantalum capacitors, substance flow analysis, rare metal tantalum, powder

\section{Introduction}

Tantalum, a gray-blue high-density hard metal, with melting point of $3017^{\circ} \mathrm{C}$ and boiling point of $5458^{\circ} \mathrm{C}$, is classified as a scarce resource. According to US Geological Survey, tantalum in the Earth's crust has limited natural reserves of 400,000 tons, with even more limited recoverable reserves of more than 43,000 tons ${ }^{1)}$. Varied industry characteristics of different countries cause varying definitions of scarce resources, but Table 1 summarizes these definitions. Scarce resources are also vulnerable to different supply policies and political considerations that could result to price volatility ${ }^{2,3)}$. It is important to understand that there are no official prices for tantalum commodities, as this metal is not traded on any metal exchange. The price is determined solely by negotia-

Table 1 Definition of scarce resource.

\begin{tabular}{|c|c|c|c|}
\hline \multicolumn{2}{|r|}{ Factor } & \multirow{2}{*}{\begin{tabular}{|l}
\multicolumn{1}{|c}{ Explanation } \\
Less content in the \\
earth's crust and \\
difficult to mine
\end{tabular}} & \multirow{2}{*}{$\begin{array}{l}\text { Scarce } \\
\text { Resources } \\
\text { Platinum }\end{array}$} \\
\hline \multirow{2}{*}{$\begin{array}{l}\text { Ore resource } \\
\text { reserves }\end{array}$} & \multirow{2}{*}{$\begin{array}{l}\text { Endowments, distribution } \\
\text { and production be } \\
\text { concentrated in a few } \\
\text { countries }\end{array}$} & & \\
\hline & & $\begin{array}{l}\text { Distributed in a few } \\
\text { countries }\end{array}$ & Tantalum \\
\hline \multirow[t]{2}{*}{ Demand } & \multirow{2}{*}{$\begin{array}{l}\text { Add a small amount in the } \\
\text { manufacturing process, } \\
\text { features and performance } \\
\text { of products dramatically } \\
\text { increase }\end{array}$} & $\begin{array}{l}\text { Exploration and } \\
\text { production in a few } \\
\text { countries }\end{array}$ & Thallium \\
\hline & & $\begin{array}{l}\text { Few production in } \\
\text { full year }\end{array}$ & Rhenium \\
\hline \multirow{2}{*}{$\begin{array}{l}\text { International } \\
\text { Factors }\end{array}$} & \multirow{2}{*}{$\begin{array}{l}\text { Affected by countries } \\
\text { supply policy and political } \\
\text { considerations. }\end{array}$} & $\begin{array}{l}\text { Suppliers Resources } \\
\text { Protectionism }\end{array}$ & Beryllium \\
\hline & & $\begin{array}{l}\text { Political restrictions } \\
\text { on exports }\end{array}$ & Indium \\
\hline \multirow[t]{2}{*}{ Technology } & \multirow{2}{*}{$\begin{array}{l}\text { Extraction, separation, } \\
\text { difficult processing that } \\
\text { only a few countries have } \\
\text { these technology }\end{array}$} & $\begin{array}{l}\text { difficulties of } \\
\text { refining and } \\
\text { processing technical }\end{array}$ & Palladium \\
\hline & & $\begin{array}{l}\text { It has cutting-edge } \\
\text { technology }\end{array}$ & Molybdenum \\
\hline
\end{tabular}

Source of the materials: T.C Chang

*Corresponding author, E-mail: tcchang@ntut.edu.tw tions between buyer and seller ${ }^{4)}$.

The major use of tantalum is for electronic components such as capacitors and high power resistors, because, as metal powder, it has a tendency to form a protective oxide surface layer. In 2012, tantalum, primarily as powder and capacitors, had global production of about 765 tons. Mozambique, Brazil, Congo, Rwanda, and Nigeria are the main producers accounting for more than $80 \%$ of the world production ${ }^{5,6)}$. Taiwan, despite relying solely on imports, is also a major player in the use of tantalum, being one of the leading countries to manufacture semiconductor wafers and optoelectronic components. It has also developed the related production and recovery technology of high purity tantalum powder. To understand the flow of the pulsating tantalum scarce resources and explore the possibility of efficient recovery ${ }^{7)}$ of precious metals, this research work concentrated on the tantalum substance flow analysis (SFA). SFA is a systematic assessment of the flows and stocks of materials within a system defined in space and time ${ }^{8)}$. One of its major applications is in resource management, specifically on analysis, planning, allocation, exploitation, and upgrading of resources ${ }^{9}$. This research aims to assess relevant flows and stocks of tantalum quantitatively, checking mass balance, sensitivities, and uncertainties. The results could be used by Taiwan government as basis for managing tantalum resource and wastes, monitoring accumulation or depletion of stocks and future environmental loadings. The results could also be used to design environmentally-beneficial goods, processes, and systems ${ }^{10)}$.

\section{Methodology and Data Source}

SFA assists decision-makers to investigate and understand storage and flow of materials in a specified system. It asks whether the flow of materials is sustainable in terms of the environmental burden it creates. It accounts for all materials and energy used in production and consumption, including the hidden flows or ecological rucksack of materials that were extracted in the production cycle but which never entered into the final products. This system includes: input, output, and stock $^{11)}$; basic analysis of the SFA program ${ }^{12,13)}$; and steps described in Fig. 1 below: 


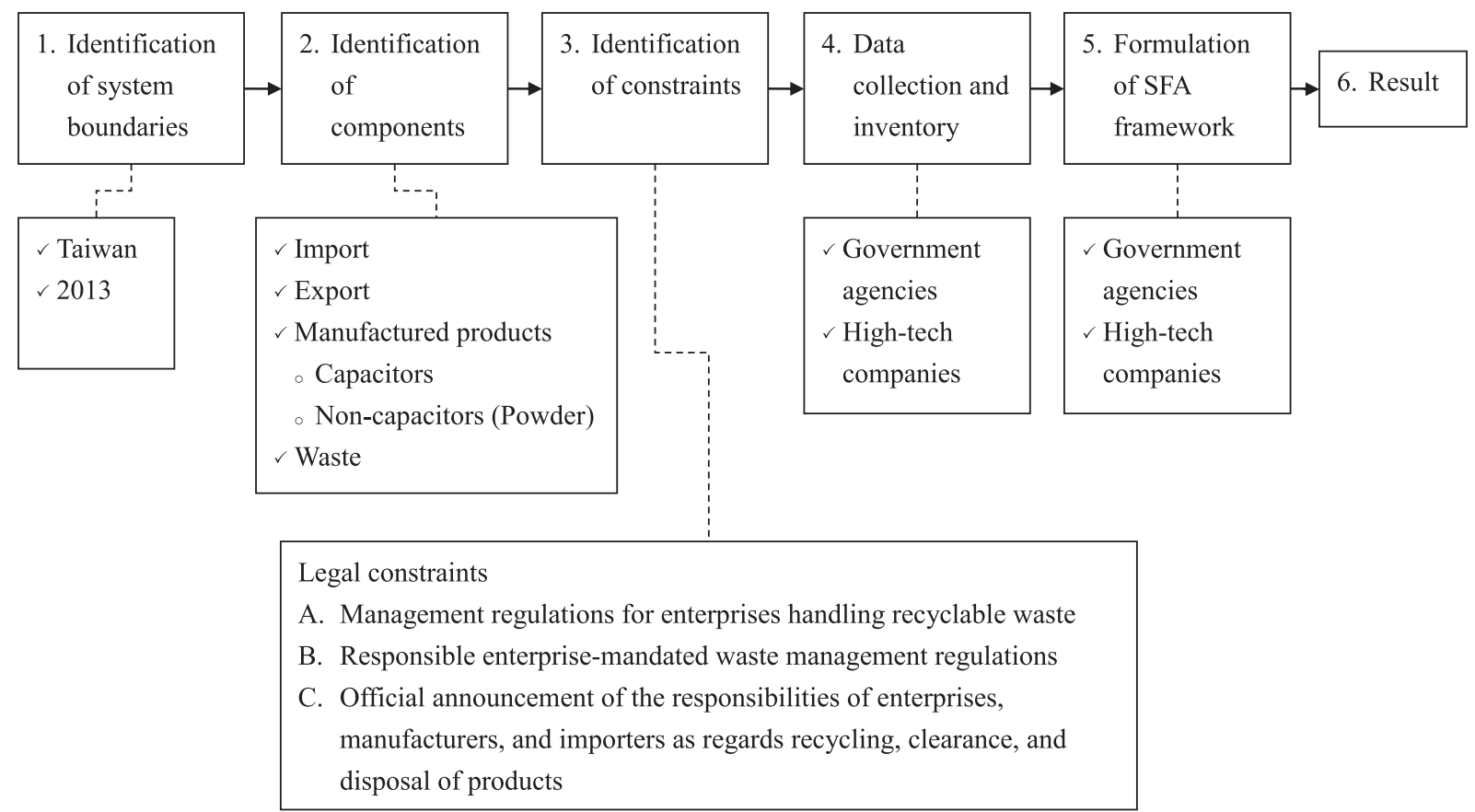

Fig. 1 SFA framework for tantalum in Taiwan in 2013.

Table 2 Tariff No. of products containing tantalum.

\begin{tabular}{|l|l|}
\hline Tariff No. & \multicolumn{1}{c|}{ Description } \\
\hline 81032000 & tantalum powders \\
\hline 81033000 & tantalum waste and scrap \\
\hline 85322100 & tantalum capacitors \\
\hline
\end{tabular}

\subsection{Identification of System Boundaries}

Tantalum SFA in Taiwan is limited to year 2013.

\subsection{Identification of components of the system}

Components include import, export, and accumulation. These components can be any of the tantalum-containing products classified as powder, waste, or capacitor based on the tariff number classifications, as shown in Table 2.

\subsection{Identification of Constraints}

Legal constraints on the responsibilities of enterprises, manufacturers, and importers as regards recycling, clearance, and disposal of products, help to reduce the uncertainty on estimation and calculation of material flow distribution and improve the accuracy of statistical scale.

At present, there is still no relevant tantalum SFA database available in Taiwan and available information was insufficient to specify uncertainty for some stock and flow data ${ }^{14)}$. However, based on the authors' judgment on data sensitivity, highly confidential data include official data from different government agencies in Taiwan, surveyed data from different companies, and estimated or validated data mainly based on official data and surveyed data. Lower confidential data include the market share of different companies that could be prejudiced by company image, among others. However, all data in the results have been validated by careful mass balance.

\subsection{Data acquisition and inventory}

Aside from literature search and market research, the two major sources of information for this study are: (1) government agencies; and (2) High-Tech companies in Taiwan.

Government agencies that provided data on import and export of tantalum in Taiwan include Ministry of Economic Affairs; Ministry of Finance; Customs Department; and Environmental Protection Administration.

High-tech companies in Taiwan are listed in Table 3. These companies provided enough information for the estimation of the total tantalum used for the manufacture of capacitors, using eqs. (1) and (2).

$$
\begin{aligned}
& T a_{\text {Tcap }}=\sum T a_{\mathrm{pdt}} \\
& T a_{\mathrm{pdt}}=\frac{S A}{M S}(0.15)
\end{aligned}
$$

where: $T a_{\text {Tcap }}$ is the total amount of tantalum in capacitors in Taiwan for the year 2013; $T a_{\text {pdt }}$ is the amount of tantalum in a specific product; $S A$ is the surveyed amount of each type of product, based on interview with different companies; $M S$ is the market share of that specific product; and 0.15 is the $15 \%$ tantalum content of capacitors as recommended by the companies to be used for the estimation, as shown in Table 4.

From the total amount of imported tantalum, the amount of non-capacitor products (powder) can be computed using eq. (3).

$$
T a_{\text {powder }}=T a_{\text {Timp }}-\left(T a_{\text {cap }}+T a_{\mathrm{w}}\right)
$$

where $T a_{\text {Timp }}$ is the total amount of imported tantalum; $T a_{\text {cap }}$ is the total amount of tantalum in capacitors; and $T a_{\mathrm{w}}$ is total amount of tantalum in waste or scrap.

Tantalum powder is high-purity tantalum powder that is free of impurities. In this study, tantalum powder or simply 
Table 3 High-tech companies surveyed.

\begin{tabular}{|c|c|c|}
\hline \multicolumn{2}{|c|}{ Tantalum-containing material } & \multirow{2}{*}{$\begin{array}{l}\text { Companies } \\
\text { Accton Technology Corporation }\end{array}$} \\
\hline \multirow[t]{10}{*}{ Import } & Tantalum Capacitors & \\
\hline & & Panasonic Taiwan Corporation \\
\hline & Tantalum Powder & Qi Xiu Enterprises Corporation \\
\hline & & Opetech Materials Corporation \\
\hline & & Solar Technology \\
\hline & & JX Nippon Mining \& Metals Corporation \\
\hline & & Solar Technology Corporation \\
\hline & Tantalum Scrap & Qi Xiu Enterprises Corporation \\
\hline & & Jii Yeeh Ding Enterprise Corporation \\
\hline & & Laurels Carry \& Leap International Corporation \\
\hline \multirow[t]{8}{*}{ Manufacture } & Semiconductor Wafers & Solar Technology Corporation \\
\hline & & Vanguard International Semiconductor Corporation \\
\hline & Switch-type Power Supply & Finesse Technology Corporation \\
\hline & & Cincon Electronics Corporation \\
\hline & Charger & Cincon Electronics Corporation \\
\hline & Rear Projection Machine & Lumens Digital Optics Incorporated \\
\hline & Other Electronic Products & Might Electronic Corporation \\
\hline & & Billion Electric Corporation \\
\hline \multirow[t]{6}{*}{ Export } & Tantalum Capacitors & ROHM Semiconductor \\
\hline & & Allreach Enterprise Corporation \\
\hline & & Satori Electric Corporation \\
\hline & Tantalum Scrap & Qi Xiu Enterprises Corporation \\
\hline & & Laurels Carry \& Leap International Corporation \\
\hline & & Yi Shibo International Business Corporation \\
\hline \multirow[t]{3}{*}{ Waste } & Tantalum Scrap & Qi Xiu Enterprises Corporation \\
\hline & & Jii Yeeh Ding Enterprise Corporation \\
\hline & & Laurels Carry \& Leap International Corporation \\
\hline
\end{tabular}

Table 4 Tantalum content of different products.

\begin{tabular}{|l|c|c|}
\hline Products containing tantalum & Tantalum content (\%) & Reference \\
\hline Tantalum pentoxide & $81.9 \%$ & molecular weight \\
\hline Tantalum powder & $100 \%$ & provided by industry \\
\hline Tantalum target & $100 \%$ & provided by industry \\
\hline Tantalum Capacitors & $15 \%$ & provided by industry \\
\hline
\end{tabular}

"powder" is used to refer to "non-capacitor" products, or products other than capacitors that are containing tantalum.

The amount of waste can be computed using eq. (4).

$$
w_{\mathrm{T}}=\sum w_{\text {imp }}+w_{\text {cap }}+w_{\text {powder }}
$$

where $w_{\mathrm{T}}$ is the total amount of tantalum in waste that will be exported; $w_{\text {imp }}$ is the amount of imported tantalum in waste or scrap; $w_{\text {cap }}$ is the amount of tantalum in the waste in the production of capacitors; and $w_{\text {powder }}$ is the amount of tantalum in the waste in the production of non-capacitor products.

The amount of tantalum accumulation in Taiwan for 2013 can then be computed using eq. (5).
Table 5 Taiwan 2013 imports of products containing tantalum.

\begin{tabular}{|l|r|r|}
\hline \multicolumn{1}{|c|}{ Product } & $\mathrm{kg}$ & \multicolumn{1}{c|}{$\%$} \\
\hline Tantalum capacitors & 200,357 & 58.87 \\
\hline Tantalum powder & 139,911 & 41.11 \\
\hline Tantalum waste and scrap & 87 & 0.03 \\
\hline Total & 340,355 & 100.00 \\
\hline
\end{tabular}

$$
T a_{\mathrm{acc}}=T a_{\mathrm{Timp}}-T a_{\mathrm{Tex}}
$$

where $T a_{\text {acc }}$ is tantalum accumulation in Taiwan; $T a_{\text {Timp }}$ is the total amount of imported tantalum; and $T a_{\mathrm{Tex}}$ is the total amount of exported tantalum.

\section{Results and Discussion}

According to the ROC Ministry of Finance Directorate General of Customs, in 2013, Taiwan imported a total of $340,355 \mathrm{~kg}$ of tantalum, as shown in Table 5. This table also shows the major categories of tantalum products: capacitors and powder. Tantalum powder represents all tantalum in Tai- 
wan other than those in capacitors. Thus, tantalum powder is also referred to as non-capacitors. This simplification was done for better tracking of tantalum flow in coordination with leading companies and government agencies in Taiwan. Tantalum capacitors accounted for $200,357 \mathrm{~kg}$ of tantalum, which is about $59 \%$ of total tantalum import. The other $41 \%$ was attributed to tantalum powder $(139,911 \mathrm{~kg})$. Out of the total imported amount, $87 \mathrm{~kg}$ was waste and scrap; and this is less than $1 \%$ of the total imported amount of tantalum.

In 2013, the domestically available tantalum capacitors were all imported, since there were no local manufacturers. Using eqs. (1) and (2), the estimated total amount of tantalum capacitors $(200,357 \mathrm{~kg})$ was computed. Table 6 shows the breakdown of this amount into specific products. eq. (2) factored in three (3) important items: SA; MS; and 0.15. SA is the surveyed amount of each type of product shown in Table 6. These amounts were the results of meticulous survey from leading high-tech companies in different industries in Taiwan (Table 3) that also disclosed their estimated market share (MS) for different products. Due to confidentiality agreement, these specific values cannot be shown in this paper. These two values, SA and MS were used to compute for the estimated total market of capacitors for each product in the different industries. The last item to be factored in was the $15 \%$ tantalum content of capacitors. This information was given by Holy Stone Enterprise Co., Ltd that claims that capacitors contain an average of $15 \%$ tantalum by weight. Equation (1) was then used to get the total amount of tantalum in capacitors in Taiwan for the year 2013. Table 6 gives the summary of the estimated amount of tantalum per product using data from industry survey, factoring in the market share of the particular company surveyed to estimate the total production in Taiwan. From Table 6, it can be seen that tantalum capacitors is mostly used for switch-type power supply.

Table 6 Estimated amount of tantalum per product based on industry survey.

\begin{tabular}{|l|l|r|}
\hline \multicolumn{1}{|c|}{$\begin{array}{c}\text { Ta-containing } \\
\text { electronic products }\end{array}$} & \multicolumn{1}{|c|}{ Manufacturers } & $\begin{array}{c}\text { Estimated } \\
\text { amount of } \\
\text { Tantalum (kg/y) }\end{array}$ \\
\hline $\begin{array}{l}\text { Switch-type power } \\
\text { supply }\end{array}$ & $\begin{array}{l}\text { Finesse Technology Co., Ltd. } \\
\text { Cincon Electronics Co., Ltd. }\end{array}$ & 72,857 \\
\hline Charger & Cincon Electronics Co., Ltd & 21,429 \\
\hline $\begin{array}{l}\text { Rear Projection } \\
\text { Machine }\end{array}$ & Lumens Integration, Inc. & 19,286 \\
\hline Motherboard & BCM Computers Co., Ltd & 9,643 \\
\hline Digital Projector & Lumens Integration, Inc. & 60,000 \\
\hline $\begin{array}{l}\text { Other electronic } \\
\text { products }\end{array}$ & Might Electronics Co., Ltd. & 200,357 \\
\hline Total & & \\
\hline
\end{tabular}

Table 7 Taiwan 2013 exports of products containing tantalum.

\begin{tabular}{|l|r|r|}
\hline \multicolumn{1}{|c|}{ Product } & \multicolumn{1}{c|}{$\mathrm{kg}$} & \multicolumn{1}{c|}{$\%$} \\
\hline Tantalum capacitors & 21,200 & 40.2 \\
\hline Tantalum powder & 28,000 & 53.1 \\
\hline Tantalum waste and scrap & 3,490 & 6.6 \\
\hline Total & 52,690 & 100.0 \\
\hline
\end{tabular}

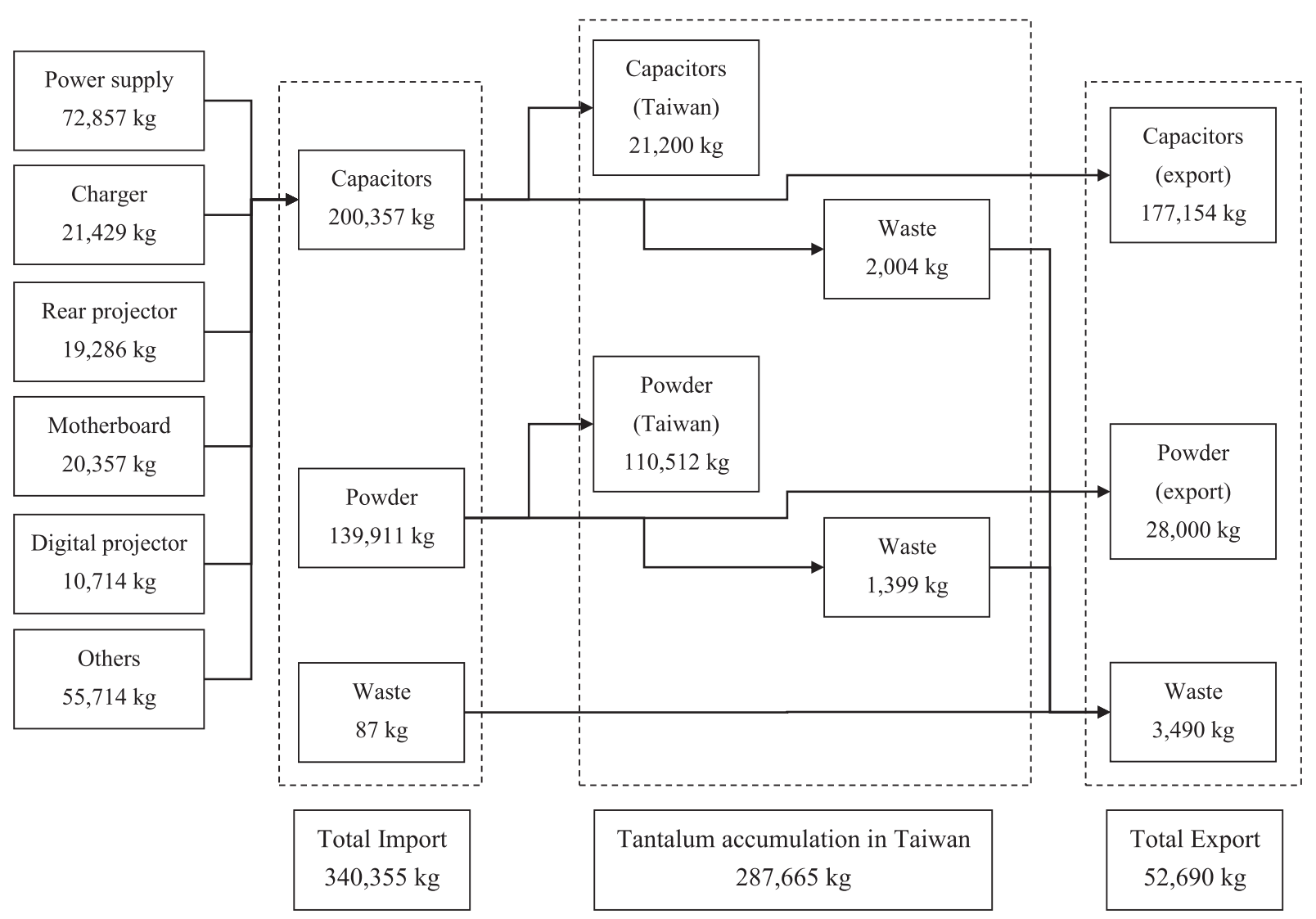

Fig. 2 SFA of tantalum in Taiwan in 2013. 
Then, using eq. (3), the amount of tantalum powder was computed. This was done by subtracting the accounted for amount of tantalum in capacitors from the total amount of imported tantalum.

Still in coordination with government agencies in Taiwan, data on exportation of tantalum was summarized in Table 7 that shows the exported amount of tantalum as capacitors, powder, or waste. The total exported amount of tantalum was $52,690 \mathrm{~kg}$. For uniformity, the categories used in the summary of importation of tantalum were used for the exportation data. Capacitors, which amounted to $21,200 \mathrm{~kg}$ of tantalum, accounted for $40.2 \%$ of exported tantalum. Non-capacitors (powder) had $28,000 \mathrm{~kg}$ and accounted for $53.1 \%$ of exported tantalum. The remaining $6.6 \%$ of exported tantalum, which is equivalent to $3,490 \mathrm{~kg}$, was wastes or scrap.

Using eq. (4), the total amount of tantalum in the waste or scrap was calculated. This is also by assuming, as recommended in the industry survey, that the waste production is $1 \%$ of the raw material. From this, the total accumulation of tantalum in Taiwan was computed using eq. (5). Figure 2 shows the complete SFA of tantalum in Taiwan for the year 2013. The total accumulated amount of tantalum in Taiwan for the year 2013 was $287,665 \mathrm{~kg}$.

\section{Conclusions}

This study investigated the amounts and directions of tantalum flow within Taiwan in 2013.

(1) Based on extensive survey and coordination with leading Taiwan companies and government agencies, the total import of tantalum in 2013 , was $340,355 \mathrm{~kg}$, while the total export was $52,690 \mathrm{~kg}$.

(2) From the total import, $287,665 \mathrm{~kg}$ of tantalum, or $84.5 \%$ remained in Taiwan economy in 2013. The major use of tantalum was in capacitor, accounting for $61.6 \%$.

(3) Accounting for waste generation, it was estimated at $3,490 \mathrm{~kg}$ of tantalum.

\section{Acknowledgements}

The data presented in this research was developed within the "Regional energy resource supply counseling application technology research and demonstration program" supported by the Industrial Development Bureau of the Ministry of Economic Affairs (Project 1030701). The authors also thank Holy Stone Enterprise Co., Ltd., Solar Technology, Inc and Sonjiu Electronic Co., Ltd. for sharing their experiences and providing valuable information regarding the use of tantalum in Taiwan.

\section{REFERENCES}

1) Larry D. Cunningham: Open-File Report 01-349, (Tantalum recycling in the United States in 1998, Flow Studies for Recycling Metal Commodities in the United States, U.S. Geological Survey).

2) T.C. Chang, C.Y. Lu and K.C. Peng: J Ind Pollution Contr 124 (2012) 175-198.

3) J. Lee, Y. Kim and J.C. Lee: J. Hazard. Mater. 241 (2012) 387-394.

4) “Tantalum - Raw Materials and Processing". Tantalum-Niobium International Study Center. http://tanb.org/tantalum.

5) "Global Mining: Mozambique among 8 Top Tantalum-producing Countries". Mozambique Resources Post. https://mozambiqueminingpost.wordpress.com.

6) "Mineral Resources Logistics". Japan Oil, Gas and Metals National Corporation (JOGMEC) (2014) pp. 192-201.

7) J.Z. Li, P. Shrivastava, Z. Gao and H.C. Zhang: IEEE T Electron Pack 27 (2004) 33-42.

8) C. Hendriks, R. Obernosterer, D. Muller, S. Kytzia, P. Baccini and P.H. Brunner: Local Environ. 5 (2000) 311-328.

9) René Kleijn and Ester van der Voet: Material Flow Accounting, Paper presented at the NTVA 4th Seminar on Industrial Ecology, 2001 pp. 14-15.

10) U. Sonesson and J. Berlin: J. Clean. Prod. 11 (2003) 253-266.

11) H. Rechberger and P.H. Brunner: Environ. Sci. Technol. 36 (2002) 809-816.

12) P. Baccini and P.H. Brunner: Metabolism of the Anthroposphere, Springer-Verlag, Berlin, Heidelberg, 1991.

13) Minnesota Pollution Control Agency (MPCA), Substance Flow Analysis of Mercury in Products, MPCA, (2001) 1-22.

14) C. Huang, J. Vause, H. Ma, Y. Li and C. Yu: J. Clean. Prod. 84 (2014) $450-458$. 